\title{
O PNDH-3 e a (im)possibilidade de novas narrativas:
}

\section{O não-agir, o não-esquecer *}

\author{
Robert Madeiro Dias ${ }^{1}$
}

Resumo: O passado se apresenta como um conjunto vivo de representações, que podem mudar tão incessantemente quanto o presente. É necessário um aprofundamento e uma busca cada vez maior de novas narrativas, novos testemunhos, novas maneiras de se escrever e pensar a história dos momentos trágicos da realidade brasileira. E cabe ao historiador "transmitir o inenarrável", como afirma Jeanne Marie Gagnebin, "manter viva a memória dos sem-nome, ser fiel aos mortos que não puderam ser enterrados." Nesta perspectiva este artigo versa sobre os direitos humanos no Brasil e os imbricamentos deste percurso no debate nacional. Temas como o Programa Nacional de Direitos Humanos - 3 (PNDH-3), a negação da Arguição de Descumprimento de Preceito Fundamental (ADPF-153) e a decisão da Corte Interamericana de Direitos Humanos (CIDH), por sua vez, tornam-se importantes para reflexão do caso nacional.

\section{Palavras-chave: novas narrativas; direitos humanos; PNDH-3; ADPF-153; CIDH}

Abstract: The past presents itself as a living set of representations, which may change as incessantly as the present. It is necessary to seek a deepening and increasing of new narratives, new witnesses, new ways of thinking and writing the history of the tragic moments of Brazilian reality. And it is historian to "convey the unspeakable," as Jeanne Marie Gagnebin, "Keeping alive the memory of the nameless, be faithful to the dead that could not be buried." In this perspective, this article focuses on human rights in Brazil and imbrications this route in the national debate. Issues such as PNDH-3, the denial of ADPF-153 and the decision of the $\mathrm{CIDH}$, in turn, become important for reflection of the Brazilian case.

Keywords: news narratives; humans rights; PNDH-3; ADPF-153; CIDH

Este texto foi produzido no bojo das discussões entre a memória, a história e o esquecimento, com os laços estreitos as propostas dos professores Cristiano Paixão e José Otávio Guimarães, no curso "Hermenêutica e Filosofia". Dentro do curso foram instigantes as

\footnotetext{
* Artigo submetido em 15 de maio/2012 e aceito para publicação em 08 de setembro/2012.

${ }^{1}$ Professor e pesquisador: tem experiência na área de História. É graduado e licenciado (2006) pela Universidade Federal do Pará (UFPA). É Especialista (2008) e, pela mesma instituição, obteve o mestrado (2009) em História Social da Amazônia. Pesquisa temas que envolvem o músico Waldemar Henrique (1905-1995) e o intelectual Mário de Andrade (1893-1945) através da análise do modo como se apropriam artisticamente da Amazônia: o tempo e o artista. O olhar viajante e o olhar nativo. Email: robertmdias@ yahoo.com.br.
}

Em Tempo de Histórias

Publicação do Programa de Pós-Graduação em História da Universidade de Brasília (PPGHIS/UnB)

No. 23, Brasília, ago. - dez. 2013

ISSN 2316-1191 
constantes aproximações entre as áreas do direito e da história. O juiz e o historiador confrontam teses, apreciam e defendem provas. Suas análises e apreciações são fundamentais e não gratuitamente historiadores têm sido convidados a participar de debates públicos para oferecer seu modo de análise sobre julgamentos e questões de violações dos direitos humanos ocorridos no passado. Estas participações foram inseridas a partir de questões relacionadas a processos de anistia, Comissões de Verdade e julgamentos de crimes contra a humanidade. Um julgamento, segundo Todorov analisa, tem ganhado proporções de espetáculo na Europa, e julgando determinados indivíduos, "julgará” o próprio passado e o evento trágico "como um todo". Casos como os de Maurice Papon (1910-2007) ou de Klaus Barbie (1913-1991), que ocorreram na França, ganharam uma repercussão muito elevadas. Historiadores ligados ao Instituto da História do Tempo Presente (IHTP), como testemunhas refletem e oferecem, ou não, o instrumental da história para as conclusões sobre tais casos. Mas

Ces procès ne sont pas exemplaires au sens où ils chercheraient à prévenir d'autres crimes similaires. Ils sont une forme de réparation tardive, sans doute légitime du point de vue des victimes, qui doit contrebalancer ce qui a été mal fait durant l'épuracion et les procès d'après-guerre. (Petit; Rousso, 1998: 63) ${ }^{2}$

Ou ainda o que foi considerado como trágico e mal meio século depois, por outras gerações, em um outro universo mental. Seguindo Henry Rousso isto seria um fenômeno de permanência da história de um período trágico e de sua memória, "uma história que não passa", que é sinônimo de obsessão, que carrega o temor de uma possível repetição. Este texto trata o caso brasileiro no que tange o "Direito à Memória e à Verdade", e a instauração de uma Comissão de Verdade no Brasil, como a possibilidade de, a partir deste intento obter-se e dar-se ênfase a novas narrativas acerca do passado ditatorial brasileiro. Ao propor, por exemplo, tornar públicas as torturas praticadas em períodos de ditadura, o projeto já revela um pretenso dever de memória que pesa frente ao já realizado sobre Direitos Humanos no país, mas que ainda assim gera pelo lado das Forças Armadas grande agitação. Mas se perguntarmos que "histórias que não passam" no contexto brasileiro, que como fenômeno permanece e inquietam as novas gerações, podemos também estar pretensamente incorrendo

\footnotetext{
2 “Estes processos não são exemplares na medida em que buscariam prevenir outros crimes similares. Eles são uma forma de reparação tardia, sem dúvida legítima do ponto de vista das vítimas, que deve equilibrar o que foi feito de errado durante a depuração e os processos do pós-guerra.” (tradução do autor)

Em Tempo de Histórias

Publicação do Programa de Pós-Graduação em História da Universidade de Brasília (PPGHIS/UnB)

No. 23, Brasília, ago. - dez. 2013

ISSN 2316-1191
} 
em um erro, pois no caso do Brasil, ao contrário da Europa, a demora em se adotar medidas características de um momento de transição, como julgamentos, por exemplo, não se dá devido a um comportamento público e privado da sociedade brasileira em padecer uma obsessão de um passado traumático, como ocorrera na França. Não há aqui "uma forma ardilosa de esquecimento, resultante do desapontamento dos atores sociais de seu poder originário de narrarem a si mesmos". Não há no Brasil de maneira generalizada, um esquecimento de fuga, expressão da má-fé, uma obscura vontade de não se informar, em suma, um querer-não-saber. "A Europa ocidental e o resto da Europa deram, depois dos anos de chumbo de meados do século XX, o espetáculo aflitivo dessa vontade obstinada. A falta excessiva de memória...” (RICOUER, 2008: 455) No Brasil não foi e não é assim, cabe mais aqui, a maneira de Ricouer, o esquecimento ativo, que pode ser imputado "aos atos de negligência, de omissão, de imprudência, de imprevidência, em todas as situações de nãoagir...” (idem. ibidem: 456) Pois, por que mesmo numa democracia o Estado brasileiro adota uma postura omissa quanto às investigações relacionadas à Guerrilha do Araguaia? Como podemos entender as querelas que surgem quando se discute a atualização brasileira frente ao cenário internacional através de uma modernização da legislação a partir do PNDH-3, por exemplo, e de revisões de leis de períodos repressores? Tratar tais temas pode revelar indícios de uma nova postura do Estado frente aos fatos trágicos de sua história, mas também, permanências. A contribuição deste trabalho, contudo, já está se tornando um lugar comum, pois acreditamos que esta demora, esta negligência, esta omissão, pelo menos até este momento, se dá pela ausência de expurgos no judiciário e nas Forças Armadas, como concluiu Anthony Pereira, que deletam permanências do regime anterior e que acaba por denunciar também que este grupo ainda possui e exerce influência no momento presente. "Pode-se sempre narrar de outro modo", afirmou Ricouer, "é impossível lembrar-se de tudo, é impossível narrar tudo." Mas, este percurso da ideologização da memória que para Ricouer passa pelos recursos de variação que o trabalho de configuração narrativa oferece torna-se de fato uma armadilha, "quando potências superiores passam a direcionar a composição da intriga e impõem uma narrativa canônica...” (idem. ibidem: 455)

É sempre possível narrar de outra forma o período ditatorial brasileiro, as causas que justifiquem tantas permanências na transição brasileira, o período de redemocratização. 
Assim, a Comissão da Verdade possibilita esta reflexão acerca de distintas versões sobre o passado, de novos testemunhos, outras narrativas geradoras de novas possibilidades de olhar aquele momento vivido, o presente e o futuro. Então, analisa Teitel algumas narrativas podem surgir do olhar de "alguns indivíduos [que] podem entender que a importância da memória foca-se na monumentalização pública enquanto outros darão uma maior valoração às memórias individuais, às biografias, aos romances históricos e aos relatórios técnicos”. Outras narrativas surgirão também dentro da política de memória focada nos valores e objetivos de cada sociedade e no modo como cada sociedade se vê dentro do processo. Segundo Teitel: “Os julgamentos podem, certamente, contribuir de modo decisivo para a formação de uma memória histórica sobre os fatos." E além dos julgamentos "alternativa importante para a formação de memória são as comissões de verdade. As comissões de verdade também atuam definindo uma narrativa histórica a partir de um determinado padrão de produção de verdades. Em todos os casos são as demandas da sociedade que estimulam as respostas do Estado." 3

Os julgamentos e as comissões de verdade que são medidas da justiça transicional, e serão retomadas mais a frente, possibilita novas narrativas, novas memórias de eventos trágicos a partir também do olhar de outros atores sociais ao trazer acontecimentos à luz. É o esquecimento que torna possível a memória, salientou Ricouer a partir de Heidegger.

De fato, dizemos do passado que ele não é mais, mas que ele foi. Com a primeira denominação, enfatizamos seu desaparecimento, sua ausência. (...) Com a segunda denominação, enfatizamos sua plena anterioridade com relação a todo acontecimento datado, lembrado ou esquecido. (...) Ninguém pode fazer com que o que não é mais não tenha sido. É ao passado como tendo sido que se vincula esse esquecimento que, como diz Heidegger, condiciona a lembrança. Compreende-se o paradoxo aparente se por esquecimento se entende o imemorial e não a inexorável destruição. (RICOUER, 2008: 450)

A partir desse entendimento, Ricouer nos esclarece uma linha do horizonte com relação à fenomenologia da memória e epistemologia da história, em que o esquecimento não é inimigo da memória e nos ajuda a refletir a dimensão seletiva da narrativa, em que nem tudo se narra, e que o que se narra antes passa por um crivo do grupo que constrói esta narrativa.

\footnotetext{
${ }^{3}$ Tratar-se de uma entrevista concedida por RUTI G. Teitel intitulada "Fazer justiça e pensar medidas de justiça num contexto de mudança política é olhar para o passado, mas também para o futuro". Incluída na Revista Anistia Política e Justiça de Transição. - N. 3 - Brasília: Ministério da Justiça, 2010. (p. 33) 
Querendo dialogar mais claramente com as atividades que desenvolvemos em sala de aula gostaria de recordar o exemplo que trabalhei por meio de meu seminário. Não estaremos incorretos se falarmos em usos e abusos de memória com relação ao nosso enfoque. Maurice Halbwachs (1877-1945) afirmou "que as memórias são construídas por grupos sociais. São os indivíduos que lembram, no sentido literal, físico, mas são os grupos sociais que determinam o que é 'memorável', e também como será lembrado. Os indivíduos se identificam com os acontecimentos públicos de importância para seu grupo.” (BURKE, 2000: 69) Na esteira desta contribuição de Halbwachs analisamos o tímido artigo de Jean Rodrigues Sales que estudou a forma como a sociedade brasileira lida com o seu passado ditatorial. Ao compararmos duas tendências interpretativas a partir do texto, uma primeira mais afinada aos militares e uma segunda relacionada aos grupos contrários ao Regime, percebemos claramente como os abusos de memória tornam-se abusos de esquecimento. Então, Sales enumera a memória celebrada, imposta, comemorada (como história oficial) sob a perspectiva militar: $1^{\circ}$ ) tendência de aceitação do discurso militar de que o golpe de abril foi uma reação ao avanço dos movimentos sociais infiltrados por ideias comunistas. Diante do perigo, o exército foi obrigado a tomar o poder. $2^{\circ}$ ) o AI-5 foi uma reação dos militares à radicalização de setores da esquerda. $3^{\circ}$ ) a opção da esquerda revolucionária pela luta armada. $4^{\circ}$ ) a noção de equivalência entre a violência praticada pelos militares e a praticada pelos militantes de esquerda, chamados de "terroristas”. (Sales Apud SILVA, 2009: 22) Pode-se notar neste percurso uma tentativa de impor uma interpretação do passado, um uso político do passado, que por sua vez, não se sustenta historicamente e que Sales buscou desconstruir. No que se refere, aos grupos de oposição ao regime têm-se uma memória social revelando torturas e crimes políticos ocorridos no período, que configura uma outra maneira de narrar o passado ficando muito claro a dívida de Ricouer para com Halbwachs. São citados no texto: o Grupo Tortura Nunca Mais, a Comissão de Mortos e Desaparecidos, o caso do estudante Edson Luis, que desencadeou a Passeata dos Cem Mil; o caso do $30^{\circ}$ congresso da UNE, em Ibiúna, interior de São Paulo; também, a greve de trabalhadores em MG e a oposição sindical de Osasco; manifestações estudantis e operária, por sua vez, reprimidas. Neste enfoque, a imagem para História, de um período de repressão, de censura, de limitações de liberdades políticas, de direitos de greves e passeatas, e da existência de grupos contrários ao governo. 
Esquecimentos e memórias à parte essa maneira de se recordar o Regime ainda possibilita de muitas maneiras "Ver uma coisa e não ver outra. Narrar um drama e esquecer outro."

\section{O PNDH-3 e a controvérsia militar (o não-agir)}

Para refletir sobre a possibilidade de outras narrativas e/ou seus impedimentos, o Brasil discute temas polêmicos, como o acesso a documentos sigilosos do governo e a criação de uma Comissão da Verdade, proposta a partir do Programa Nacional de Direitos Humanos3, o PNDH-3. Este programa será aqui discutido fundamentalmente em seu Eixo Orientador VI que trata exatamente do "Direito à Memória e à Verdade" que foi o que causou maior polêmica. Antes de mais, é preciso ressaltar a sonolência do Estado brasileiro sobre o assunto. Seus avanços significativos estão pautados na lei 9.140, de 04 de dezembro de 1995, em virtude dos desaparecimentos forçados, e na lei 10.559, de 13 de novembro de 2002, em virtude da restituição de perdas materiais. Estas leis visam tão somente o pagamento de indenizações, não havendo avanço significativo no debate sobre direitos humanos, realizando pouco, no que diz respeito a esclarecimentos sobre as condições em que ocorreram os crimes e, menos ainda sobre possíveis julgamentos de carrascos da ditadura. O PNDH-3 é um recurso que pode possibilitar uma nova maneira do Estado Brasileiro se posicionar com relação à memória das ditaduras ocorridas no país. Sob a esteira dos direitos humanos, a diretriz n. 23 estabelece o "Reconhecimento da memória e da verdade como Direito Humano da Cidadania e dever do Estado.” Tendo como objetivo estratégico I:

Promover a apuração e o esclarecimento público das violações de Direitos Humanos praticadas no contexto da repressão política ocorrida no Brasil no período fixado pelo artigo $8^{\circ}$ do ADCT da Constituição, a fim de efetivar $o$ direito à memória e à verdade histórica e promover a reconciliação nacional. (Brasil. PNDH-3, 2010: 173)

Porém, tão logo a ideia de trazer à público a memória impedida do regime militar um grupo seleto inquietou-se, e de tal forma que os comandantes do Exército, Enzo Martins Peri, e da Aeronáutica, Juniti Saito, ameaçaram pedir demissão caso alguns trechos do programa não fossem revogados. Dirá Nelson Jobim, então ministro da Defesa que o plano seria "insultuoso, agressivo e revanchista" contra as Forças Armadas. Seguido pelos presidentes do Clube Militar, que afirmaram em um comunicado que tal programa causaria divisão entre os brasileiros e traria à tona "sequelas deixadas por ambos os lados". É importante observar o 
incomodo que o programa oferece a determinados setores da cúpula militar, que rapidamente exigiram modificações no texto original, conseguidas a partir de um novo decreto que suprimiu a expressão "repressão política". ${ }^{4}$ Este decreto teve como objetivo criar um anteprojeto visando a Comissão Nacional da Verdade. Pelo texto original a Comissão teria, enfim, o objetivo de "examinar as violações aos direitos humanos praticadas no período fixado no artigo $8^{\circ}$ do Ato das Disposições Constitucionais Transitórias a fim de efetivar o direito à memória e à verdade histórica e promover a reconciliação nacional.” Mantendo, por sua vez, trechos como: "identificar, e tornar públicas as estruturas utilizadas para a prática de violações de direitos humanos, suas ramificações nos diversos aparelhos de Estado, e em outras instâncias da sociedade". Fica nítida a reação adversa por parte dos militares na discussão desta memória ao priorizar uma maneira de narrar e interpretar os fatos.

$\mathrm{Na}$ apresentação do Programa Nacional afirma-se claramente que "o Brasil fez uma opção definitiva pelo fortalecimento da democracia." Assinado por 31 ministérios, a apresentação assinada pelo então presidente da República Luis Inácio Lula da Silva esclarece que o PNDH-3 incorpora "resoluções da $11^{a}$ Conferência Nacional de Direitos Humanos e propostas aprovadas nas mais de 50 conferências nacionais temáticas, promovidas desde 2003”, abrangendo os diversos temas..$^{5}$ A apresentação do PNDH-3 também esclarece a contribuição, no que se refere ao eixo orientador VI, de discussões, debates e seminários que ocorreram no Brasil sobre o Holocausto e a memória de Auschwitz. (Brasil. PNDH-3, 2010: 11)

Este Programa é bastante amplo e foi formulado a partir de eixos orientadores, sendo o VI a fazer referência ao Direito à Memória e à Verdade. ${ }^{6}$ Neste, a apresentação afirmar que

No tocante à questão dos mortos e desaparecidos políticos do período ditatorial, o PNDH-3 dá um importante passo no sentido de criar uma Comissão Nacional da Verdade, com a tarefa de promover esclarecimento público das violações de Direitos Humanos por agentes do Estado na repressão aos opositores. Só conhecendo inteiramente tudo o que se passou naquela fase lamentável de nossa vida republicana o Brasil construirá

\footnotetext{
${ }^{4}$ Uma das principais queixas dos militares é que o plano não prevê a investigação de excessos praticados por grupos de esquerda contra o regime.

5 Temas como “- segurança alimentar, educação, saúde, habitação, igualdade racial, direitos da mulher, juventude, crianças e adolescentes, pessoas com deficiência, idosos, meio ambiente etc -”.

${ }^{6}$ Os eixos obedecem à seguinte ordem, eixo I: Interação democrática entre Estado e sociedade civil; eixo II: Desenvolvimento e Direitos Humanos; eixo III: Universalizar direitos em um contexto de desigualdades; eixo IV: Segurança pública, acesso à justiça e combate à violência; eixo V: Educação e cultura em Direitos Humanos e eixo VI: Direito à Memória e à Verdade. Idem. (p. 18).
}

Em Tempo de Histórias

Publicação do Programa de Pós-Graduação em História da Universidade de Brasília (PPGHIS/UnB)

No. 23, Brasília, ago. - dez. 2013

ISSN 2316-1191 
dispositivos seguros e um amplo compromisso consensual - entre todos os brasileiros - para que tais violações não se repitam nunca mais. (Brasil. PNDH-3, 2010: 13)

Este programa é apenas um exemplo que entra em cena com a proposta de tornar públicas violações aos direitos humanos, como torturas, sequestros e desaparecimentos forçados e que expõe um anseio da sociedade. Há uma pressão internacional e uma mentalidade social que aspira "a necessidade de 'lembrar' o passado, de atribuir culpas e de reconhecer o sofrimento das vítimas da repressão", como confirmou o estudo de Alexandra Barahona de Brito (2009: 56). Em um estudo comparativo, Ivan Cláudio Marx, (Marx Apud SILVA: 2009) por sua vez, analisa de maneira comparada as medidas adotadas pela Argentina e o Brasil no contexto de justiça transicional e constata a pouca atuação do estado brasileiro no avanço às medidas internacionais de combate a crimes contra a humanidade. Mezarobba pontua quatro obrigações que cabem ao Estado no caso de violações de direitos humanos. 1) investigar, processar e punir os violadores de direitos humanos; 2) revelar a verdade para as vítimas, seus familiares e toda a sociedade; 3) oferecer reparação adequada e 4) afastar os criminosos de órgãos relacionados ao exercício da lei e de outras posições de autoridade." (MEZAROBBA, 2009: 168) Dentre estas medidas o Estado tem avançado mais no terceiro item, já as demandas pela busca da verdade (a revelação das condições em torno dos crimes), a apuração das responsabilidades dos envolvidos e a localização e identificação dos despojos das vítimas, que é o viés mais enfatizado pelos familiares das vítimas, tem recebido pouco avanço e interesse por parte do Estado brasileiro.

Neste cenário, Mezarobba justifica o título de seu texto, "Anistia e reparação: uma combinação imprópria” ao afirmar a luta pela anistia na sociedade brasileira, mas uma anistia imprópria na medida em que não possibilitou avanços na busca dos responsáveis, de forma que atua como um obstáculo aos direitos humanos, não constituindo-se em obstáculos para o pagamento de indenizações, mas o sendo quanto a apuração e punição de responsáveis, por práticas de torturas, prisões, sequestros, desaparecimento forçado, assassinatos, etc.

O primeiro PNDH data de onze anos pós-ditadura no país, e buscava a garantia de direitos civis e políticos. Foi revisado em 2002, sendo incorporadas questões referentes dos direitos econômicos, sociais e culturais. Assume uma terceira versão na perspectiva de 
consolidar a promoção dos Direitos Humanos no Brasil. O objetivo, enfim, seria apresentar as bases de uma política de Estado para os Direitos Humanos. Suas medidas serão fundamentais, quando no limite o texto não sombrear o objetivo central da sociedade brasileira contemporânea que é ver no corpo do texto de modo claro, a possibilidade de reconstituir a história da repressão, as estruturas, as circunstâncias relacionadas às práticas de violações de direitos humanos, fundamentalmente ocorridas no Regime Militar que vigorou no país de 1964 a 1985, não estendendo de modo pouco justificável para outros períodos, como está definido; cabe também a reflexão sobre o risco do "modelo memorial não levar a melhor sobre o modelo histórico, e com ele, um uso completamente diferente do passado, imprevisível e caprichoso" como ressaltou Ricouer a partir de Todorov. (RICOUER, 2008: 103)

\section{Justiça de transição, a ausência de expurgos no judiciário (o não-mudar)}

Para entendermos a participação militar e a influência que ainda exerce no contexto atual é imprescindível observarmos a contribuição do estudo de Anthony Pereira sobre a justiça transicional e a herança da legalidade autoritária no Brasil. Ao analisar comparativamente os casos da Argentina, do Chile e do Brasil, o autor percebe a existência de duas instituições de grande importância adotadas após o fim de regimes autoritários: "uma comissão oficial criada pelo governo para investigar e relatar sobre as violações dos direitos humanos ocorridas no passado ('a comissão da verdade') e a iniciativa de levar os responsáveis a julgamento.” Os resultados no Brasil ainda são minimalistas. O motivo pode ser estendido ao fato de que "no Brasil, as organizações conservadoras do judiciário e das forças armadas mantiveram-se praticamente incólumes, apesar da transição para a democracia." (PEREIRA, 2010: 239) Um dado significativo do estudo de Pereira é a ausência, na mudança de regime, de um partido de oposição coerente que pudesse influir em âmbito nacional, neste caso, é significativo recordarmos o fato de que até pouco tempo o primeiro presidente civil do Brasil, por exemplo, José Sarney, diferente dos colegas da Argentina e do Chile, não ser um crítico do regime militar. "Muito pelo contrário, havia sido um de seus aliados mais entusiásticos e membro do partido político que apoiava o regime, a Arena (Aliança Renovadora Nacional), e, mais tarde, do PDS (Partido Democrático Social).” 
(idem. ibidem: 240) Sarney que até então, como presidente do Senado Federal lutava pelo "sigilo eterno" dos documentos oficiais do governo. Após a transição brasileira, conclui Pereira, o judiciário e as forças armadas resistiram "à implantação de reformas que pudessem vir a afetar suas organizações." (idem. ibidem: 252) "No contexto da transição negociada," como já se argumentou ser o caso do Brasil, “o regime autoritário retém certo poder sobre a transição. As novas democracias precisam levar em consideração as forças autoritárias e sua influência na sociedade.” (OLSEN; PAYNE; REITER. 2009: 167) E é neste cenário que vislumbramos permanências, que cabe questionar se não estão tais influências presentes através da negação, por parte do Supremo Tribunal Federal, de Arguição de Descumprimento de Preceito Fundamental, perpetrado pela Ordem dos Advogados do Brasil, que visava rever a interpretação dada à Lei n. 6.683, de 28 de agosto de 1979, a lei de anistia.

\section{O irreparável, o imprescritível, o imperdoável: como esquecer?}

Nos exercícios de reflexão em sala de aula parecemos apresentar um consenso de que o Brasil pode estar iniciando seu trabalho de luto, um trabalho de memória sobre um período trágico, a interrogação avança, por sua vez, sobre em que medida este processo significa superar os traumas do período da repressão. Para continuarmos nossa reflexão seguiremos, uma vez mais, as importantes reflexões do filósofo francês Paul Ricouer acerca da temática do perdão difícil para mais uma vez observarmos as dificuldades, que se colocam ao Brasil, quando verdade e reconciliação estão em debate, quando o judiciário nega a ADPF-153, e resiste a acatar a decisão da Corte Interamericana de Direitos Humanos, como logo veremos.

No capitulo, "O Perdão Difícil” Ricoeur afirma: "a falta é o pressuposto existencial do perdão". Na esteira de Jean Nabert, filósofo racionalista, ressalta a experiência da falta ao lado das do fracasso e da solidão, e na de Karl Jaspers, a culpabilidade estaria entre situações limites, tais como a morte, o sofrimento, o combate. Ricoeur tem a preocupação de enfatizar uma estrutura fundamental da imputabilidade de nossos atos. "De fato, não pode haver perdão a não ser que se possa acusar alguém, presumi-lo ou declará-lo culpado. E apenas se podem acusar atos imputáveis a um agente que se considera como seu autor verdadeiro." A imputabilidade é essa capacidade associativa do verbo modal poder: "posso falar, agir, narrar,

Em Tempo de Histórias

Publicação do Programa de Pós-Graduação em História da Universidade de Brasília (PPGHIS/UnB)

No. 23, Brasília, ago. - dez. 2013

ISSN 2316-1191 
levar meus atos à minha conta - eles podem ser a mim imputados.” (RICOUER, 2008: 467) É nesta região da imputabilidade que a falta, a culpabilidade deve ser buscada, nessa região entre o ato e o agente. No dano causado a outrem, na transgressão a qualquer regra, ou ainda no injustificável que "designa esse excesso do não-válido, esse além das infrações medidas em função das regras que a consciência moral reconhece: tal crueldade, tal baixeza, tal desigualdade extrema nas condições sociais me comovem sem que eu possa designar as normas violadas.” (idem: 470 - 471) Então “os males são desgraças inqualificáveis para aqueles que a suportam". Para os que a sofreram na forma de tortura, ocasionando danos materiais e psicológicos, gerando traumas, muitas vezes danos irreversíveis. Muitas narrativas, testemunhos demasiados ainda a ser ouvidos para fazer frente às muitas falas militares que buscam motivos diversos para negar ou diluir sua imputabilidade.

O agente a quem estes atos são imputáveis, "o excesso próprio do injustificável constitui outro tipo de ilimitação que não a da causalidade insondável cavada por trás dos atos na intimidade do sujeito: é uma ilimitação simétrica aquela do dano feito a outrem, cuja possibilidade é inscrita nesse dano por excelência, a saber, o assassinato, a morte não sofrida mas infligida ao outro, em suma, 'esse mal que o homem faz ao homem. "” "O injustificável exagera a experiência da falta", "o ódio mal dá a medida, e faz explodir a própria ideia de afecção do sujeito por suas próprias ações.” Assim, Ricoeur afirma que é no extremo do mal infligido a outrem, na ruptura do vinculo humano, que se torna o indício desse outro extremo, o da maldade íntima do criminoso. É nesse ponto que se anunciam noções como o irreparável do lado dos efeitos, o imprescritível do lado da justiça penal, o imperdoável do lado do juízo moral. (idem: 471)

Na equação do perdão Ricoeur analisa uma trajetória focada em dois pólos, o da falta e o do perdão. O perdão não é fácil, porém não é impossível. Todavia se ele existe deveria permanecer na ordem do "excepcional e extraordinário, à prova do impossível." Pois o perdão, “dirige-se ao imperdoável ou não é. Ele é incondicional, ele é sem exceção e sem restrição. Ele não pressupõe um pedido de perdão: 'Não se pode ou não se deveria perdoar, apenas há perdão, se houver, onde há algo imperdoável. "” (Derrida Apud RICOUER, 2008: 
474) ${ }^{7} \mathrm{O}$ perdão, assim, não pressupõe a encenação, nem uma determinada finalidade, ele simplesmente é perdão. Mas, Ricoeur não crê exatamente num perdão, e sim, no trabalho de luto do qual a sociedade precisaria fazer para se libertar do passado repressor e superar seus traumas. Se Derrida pensa o perdão como um atributo divino, o pensamento de Ricoeur está assentado neste trabalho de memória e neste trabalho de luto, que pode igualar-se ao dever de memória, enquanto dever de justiça.

Anistiar segundo o Direito Penal é conceder perdão jurídico no sentido de anulação de todo e qualquer dispositivo de atuação da justiça penal. Institucionalmente, a anistia opera para o passado, apagando o crime e extinguindo todos os efeitos penais da sentença. Por ela declara-se extinta a punibilidade. Mas anistiar também pode ser visto como um não perdão por parte das vítimas. Pode uma instituição perdoar? Até onde esta ação seria válida? Assim, e adotando este pensamento, pensamos a possibilidade de uma Comissão da Verdade no Brasil não como uma busca do perdão, mas acima de tudo, como um instrumento de reflexão de um período trágico da história brasileira. Como um instrumento que ofereça ao Brasil uma posição mais consolidada acerca dos direitos humanos. Como uma oportunidade, ainda de novos testemunhos, de novas narrativas de familiares e/ou vítimas. Podemos ainda pensar a Comissão da Verdade como um trabalho de luto que a sociedade precisaria fazer para purgar os males de seu passado trágico e avançar na perspectiva de não repeti-los.

Rever a Lei de Anistia no Brasil seria um avanço. A decisão da Corte Interamericana de Direitos Humanos (CIDH) que condena o país a investigar e processar crimes contra a humanidade praticados por agentes do Estado durante a Guerrilha do Araguaia declara, por exemplo, por unanimidade, que:

As disposições da Lei de Anistia brasileira que impedem a investigação e sanção de graves violações de direitos humanos são incompativeis com a Convenção Americana, carecem de efeitos jurídicos e não podem seguir representando um obstáculo para a investigação dos fatos do presente caso (da Guerrilha do Araguaia), nem para a identificação e punição dos responsáveis, e tampouco podem ter igual ou semelhante impacto a respeito de outros casos de graves violações de direitos humanos consagrados na Convenção Americana ocorridos no Brasil. (CIDH, 2010: 114)

\footnotetext{
${ }^{7}$ Ver também (KRAPP, 2008)
} 
Mas em que termos a anistia se deu no Brasil, Heloisa Amélia Greco (Greco Apud SILVA: 2009) apresenta-a em duas concepções que são opostas e excludentes: a Anistia como resgate da memória e direito à verdade, como luta contra o esquecimento e recuperação das lembranças, por isso uma anistia-anamnese de uma memória instituinte e anistia como esquecimento e pacificação, da concessão e do consenso, uma anistia-amnésia, de uma memória instituída. Greco situa a Lei n. 6.683, de 28 de agosto de 1979, como uma representação da anistia-amnésia, como estratégia de esquecimento e silenciamento, e que na chamada reciprocidade conferiu impunidade e inimputabilidade a agentes do Estado que perpetraram torturas, assassinatos e desaparecimentos durante a ditadura. (Greco Apud Silva, 2009: 210-211) E argumenta ainda que a lei foi um importante ponto de inflexão no movimento pela anistia: "de sua aprovação adveio certo esvaziamento dos movimentos". (idem: 212)

Os avanços no sentido de modificação desta legislação tem andado a passos curtos. A negação da $\mathrm{ADPF}$ - 153 é o exemplo. Ação proposta pela OAB esta tinha em mira a interpretação dada ao Art.1 $1^{\circ} \S 1$ da Lei $n^{\circ}$ 6.683, de 28 de agosto de 1979, que anistiou tanto presos políticos como seus algozes, com o argumento de que o crime destes seriam crimes conexos ao daqueles, o $\S 1^{\circ}$ desse mesmo artigo esclarece: "Consideram-se conexos, para efeito deste artigo, os crimes de qualquer natureza, relacionados com crimes políticos ou praticados por motivação política". (ADPF-153, OAB: 01) Mas se passássemos a compreender que os crimes praticados pelos militares, na verdade, seriam crimes comuns e não conexos aos crimes políticos atribuídos aos opositores do regime, então a lei de anistia não poderia incluir em seu alcance os militares. "Ela não abrange os agentes públicos que praticaram, durante o regime militar, crimes comuns contra opositores políticos, presos ou não." (idem: 10) Dessa forma, a ADPF-153 pediu uma "interpretação conforme a Constituição, de modo a declarar, à luz dos seus preceitos fundamentais, que a anistia concedida pela citada lei aos crimes políticos ou conexos não se estende aos crimes comuns praticados pelos agentes da repressão contra opositores políticos, durante o regime militar (1964/1985).” (idem: 17)

Ora, 
Em 29 de abril de 2010, o Supremo Tribunal Federal, por sete votos a dois, declarou a improcedência da Arguição de Descumprimento de Preceito Fundamental, interposta pela Ordem dos Advogados do Brasil, e afirmou a vigência da Lei de Anistia e a constitucionalidade da interpretação do parágrafo $1^{o}$ do seu artigo $1^{o}$ (supra pars. 44 e 58). Essa decisão tem eficácia erga omnes e efeito vinculante e contra ela não cabe nenhum recurso. Entre outros fundamentos, o voto do Ministro Relator destacou que a Lei de Anistia foi "uma lei-medida", não uma regra para o futuro e, como tal, deve "interpretar-se em conjunto com o seu texto, a realidade no e do momento histórico no qual foi criada e não a realidade atual”. Nesse sentido, a Lei implementou "uma decisão política [do] momento da transição conciliada de 1979", uma vez que "foram todos absolvidos, uns absolvendo-se a si mesmos". A lei, efetivamente, incluiu na anistia os "agentes políticos que praticaram crimes comuns contra opositores políticos, presos ou não, durante o regime militar". O acordo político realizado pela classe política, que possibilitou a transição para o Estado de direito "resultou em um texto de lei [e, portanto,] quem poderia revê-lo seria exclusivamente o Poder Legislativo. Ao Supremo Tribunal Federal não incumbe alterar textos normativos concessivos de anistias". Finalmente, a respeito da recepção ou não da Lei No. 6.683/79 na nova ordem constitucional democrática, salientou que "a [L]ey [de Anistia] de 1979 já não pertence à ordem decaída. Está integrada na nova ordem [constitucional]. Constitui a origem da nova norma fundamental" $e$, portanto, "sua adequação à Constituição de 1988 resulta inquestionável. (CIDH, 2010: 51)

Para efeitos de esclarecimento, a Arguição de Descumprimento de Preceito Fundamental é um instrumento jurídico que visa aos preceitos fundamentais da Constituição. Direito à vida, à liberdade, à igualdade, à segurança, de que todos são iguais perante a lei, são assegurados pela Constituição Brasileira, assim como o preceito claro de não se ocultar a verdade. "A Constituição da República declara, enfaticamente, que 'todos têm direito de receber dos órgãos públicos informações de seu interesse particular, ou de interesse coletivo ou geral (art. 5, XXXIII)’”. (ADPF-153: 12-13) Assim é contraditório ocultar-se a verdade impedindo que a população brasileira tome conhecimento da identidade dos responsáveis pelos horrores perpetrados, durante dois decênios, pelos que haviam empalmado o poder.

Quando o regime autoritário tem o poder suficiente para negociar sua saída, a sociedade civil pode carecer de poder político para exigir julgamentos. Temendo as ameaças dos espoliadores (...) uma nova democracia provavelmente promulgará uma anistia.

Em Tempo de Histórias

Publicação do Programa de Pós-Graduação em História da Universidade de Brasília (PPGHIS/UnB)

No. 23, Brasília, ago. - dez. 2013

ISSN 2316-1191 
Assim, uma vez mais, parece que a explicação a esta postura do Supremo Tribunal Federal não está no direito, mas sim na política, na ausência de expurgos no judiciário e nas Forças Armadas, na forma negociada como se deu a transição no Brasil, num momento que historicamente é conhecido como o "processo de redemocratização". Larissa Prado enfatizou na política a justificativa à interpretação dada a Lei de Anistia estendo-a aos militares, em que arguiu-se, ser a garantia de um retorno pacífico à democracia (Prado Apud SILVA: 2009). O texto da CIDH encaminha a discussão nos termos de que houve um acordo político e que caberia ao Poder Legislativo alterá-lo, caso ocorra. ${ }^{8}$ Sobre tal decisão, em manter a forma na qual a Lei de Anistia foi interpretada e aplicada, a CIDH considerou que a mesma "afetou o dever internacional do Estado de investigar e punir as graves violações de direitos humanos, ao impedir que os familiares das vítimas fossem ouvidos por um juiz"; violou o direito à proteção judicial "precisamente pela falta de investigação, persecução, captura, julgamento e punição dos responsáveis pelos fatos". Desta forma, o Estado também descumpriu sua obrigação de adequar seu direito interno, em vistas ao caráter permanente do crime de desaparecimento. (CIDH-2010: 64)

Mas será o PNDH-3, o resultado da pressão internacional frente ao Brasil para que examine sua postura frente aos períodos de recessão? Que posição o país tem adotado frente a seu passado trágico? O documento é um indício de que há um interesse do Estado em se atualizar quanto à legislação internacional que se refere aos Direitos Humanos. Mas ainda muito timidamente. Como confirma a decisão da CIDH: o Brasil quanto a Guerrilha do Araguaia apresentou pouco no sentido de avançar no conhecimento deste passado, pelo contrário, em suas considerações acerca da "Incompetência temporal do Tribunal" alegada, o Estado brasileiro arguiu constantemente o reconhecimento da Corte para "fatos posteriores" a 10 de dezembro de 1998, o que subjaz o entendimento de que a ratificação da Convenção Americana de Direitos Humanos se deu na especificidade de que demandas anteriores, como

\footnotetext{
${ }^{8}$ O ministro Eros Grau, "afirmou (...) que caberia ao Legislativo, e não ao Judiciário, uma possível revisão ou revogação da Lei de Anistia (que, para ele, acompanhariam as mudanças da sociedade). Foi o que ocorreu, de acordo com o relator, em outros países da América Latina, como Chile, Argentina e Uruguai." (p. 38 - 42, do relatório referente a decisão da ADPF-153/DF, pelo STF). E a fala do ministro Gilmar Mendes: "Saliento aqui a importância de homenagear as pessoas que acreditaram na política como o caminho para a superação de impasses, guiando, por meio de uma atuação segura e constante, o nosso 'processo de abertura. "” (p. 240). Ver também o item 130 da decisão da CIDH, onde o Estado alega "que a punição dos crimes contra os direitos humanos, depois de terminadas as hostilidades, pode chegar a representar um obstáculo ao processo de transição." (p. 49)
}

Em Tempo de Histórias

Publicação do Programa de Pós-Graduação em História da Universidade de Brasília (PPGHIS/UnB)

No. 23, Brasília, ago. - dez. 2013

ISSN 2316-1191 
as que englobariam os anos de chumbo do Regime Militar, não seriam investigados. E a Corte se pronunciou no sentido de que o Tribunal pode se manifestar sobre "fatos que ocorreram ou persistiram a partir de 10 de dezembro de 1998". Por tanto, "a Corte tem competência para analisar os supostos fatos e omissões do Estado, ocorridos depois da referida data, relacionados com a falta de investigação, julgamento e sanção das pessoas responsáveis, inter alia, pelos alegados desaparecimentos forçados e execução extrajudicial;" (CIDH, 2010: 10) ${ }^{9}$ Esses fatos, essas omissões e restrições que permanecem por parte do Estado, revelam-se em contraditório frente ao seu objetivo de ser membro permanente do Conselho de Segurança da ONU, organização internacional que realizou críticas ao Estado Brasileiro frente à maneira de lidar com o seu passado. ${ }^{10}$ A proposta da Comissão da Verdade pode representar uma forma distinta do Estado brasileiro de se posicionar frente à sua história e significar um avanço real do Brasil quanto aos Direitos Humanos ou ainda uma simples maneira de demonstrar que esta fazendo o seu dever de casa.

Ante a decisão do Estado Brasileiro de não atualizar seu direito interno, a CIDH pronunciou-se nos termos, em que estima

oportuno recordar que a obrigação de cumprir as obrigações internacionais voluntariamente contraídas corresponde a um princípio básico do direito sobre a responsabilidade internacional dos Estados, respaldado pela jurisprudência internacional e nacional, segundo o qual aqueles devem acatar suas obrigações convencionais internacionais de boa-fé (pacta sunt servanda) ${ }^{11}(\mathrm{CIDH}, 201: 10)$

\footnotetext{
${ }^{9}$ A Corte tem competência para analisar ainda "a alegada falta de efetividade dos recursos judiciais de caráter civil a fim de obter informação sobre os fatos; as supostas restrições ao direito de acesso à informação, e o alegado sofrimento dos familiares." (CIDH. 2010: 10).

${ }^{10}$ As criticas foram direcionadas contra a resistência do Brasil em lidar como seu passado e a forma pela qual informações do Estado estão sendo tratadas. A crítica está presente no Estadão.com. br: "A Organização das Nações Unidas (ONU) alerta que o Brasil estará violando suas obrigações internacionais se não der acesso aos arquivos da ditadura para vítimas de tortura; critica a falta de transparência do governo e vai enviar um comunicado oficial para que as autoridades 'reconsiderem' suas posições em relação à anistia aos crimes do passado e ao fechamento dos arquivos." Consultado em 01 de julho de 2011, em <http://br.noticias.yahoo.com/onu-critica-brasil-anistia-sigilo-pap\%C3\% A9is-143000499.html>

11 "Como já salientou esta Corte e conforme dispõe o artigo 27 da Convenção de Viena sobre o Direito dos Tratados de 1969, os Estados não podem, por razões de ordem interna, descumprir obrigações internacionais. As obrigações convencionais dos Estados Parte vinculam todos seus poderes e órgãos, os quais devem garantir o cumprimento das disposições convencionais e seus efeitos próprios (effet utile) no plano de seu direito interno." Idem. ibidem. (p.66)
}

Em Tempo de Histórias

Publicação do Programa de Pós-Graduação em História da Universidade de Brasília (PPGHIS/UnB)

№. 23, Brasília, ago. - dez. 2013

ISSN 2316-1191 
O Tribunal valora as medidas de reparação e de não repetição adotadas pelo Brasil, embora considere que estas medidas não são suficientes, uma vez que omite o acesso a justiça por parte dos familiares das vítimas.

Na sentença a CIDH defende ainda com mais veemência a posição de que "à luz das obrigações gerais", "Os Estados Parte têm o dever de adotar as providências de toda índole, para que ninguém seja privado da proteção judicial do exercício do direito a um recurso simples e eficaz." O Estado deveria adotar todas as medidas para "deixar sem efeito as disposições legais que poderiam contrariá-lo, como são as que impedem a investigação de graves violações de direitos humanos, uma vez que conduzem à falta de proteção das vítimas e à perpetuação da impunidade, além de impedir que as vítimas e seus familiares conheçam a verdade dos fatos." (CIDH, 2010: 65) Assim simplesmente caberia ao Estado cumprir suas obrigações internacionais.

Dessa forma, o próprio Estado passou a ser alvo do olhar da CIDH, aparente e infelizmente ainda demonstrando pouca disposição ao avanço positivo deste tipo de demanda. O debate está lançado. A eficácia do direito internacional é limitada e discute-se internamente sobre seu aceite ou não. Cecília Macdowell a partir do andamento dos casos Hansen e da Guerrilha do Araguaia, e comumente atenta ao trabalho da justiça que "além de servir de fonte à memória e à história", também é "uma forma de trabalho da memória", enfatiza a resistência do Estado brasileiro "em reconhecer a sua responsabilidade" (MACDOWELL SANTOS, 2009: 472) e pontua dentre as causas que justifiquem essa posição do Estado, que até o momento ignora o papel da mobilização jurídica transnacional dos direitos humanos, que a nova democracia, não rompeu necessariamente com as estruturas de poder que dava sustentação ao regime anterior; tampouco veio a transformar as culturas jurídicas de todos os setores do Estado e da sociedade. ${ }^{12}$

Todos estes avanços e retrocessos constituem um alargamento do passado em questão. O regime militar torna-se uma questão em aberto e constante, que vem a tona mesmo num momento em que o debate parece já esgotado. O passado, de fato, se apresenta como um conjunto vivo de representações, que podem mudar tão incessantemente quanto o presente. É necessário um aprofundamento e uma busca cada vez maior de novas narrativas, novos

\footnotetext{
${ }^{12}$ Idem. ibidem. (p. 492). Desta autora, ver também SANTOS, Cecília Macdowell. (2010: 124-151) Em Tempo de Histórias Publicação do Programa de Pós-Graduação em História da Universidade de Brasília (PPGHIS/UnB) No. 23, Brasília, ago. - dez. 2013 ISSN 2316-1191
} 
testemunhos, novas maneiras de se escrever e pensar a história deste momento trágico da realidade brasileira. O historiador "precisa transmitir o inenarrável", disse Jeanne Marie Gagnebin, "manter viva a memória dos sem-nome, ser fiel aos mortos que não puderam ser enterrados." (GAGNEBIN, 2006: 47) Os tribunais nos oferecem processos que dentro de uma verdade jurídica nos chama a atenção como fontes preciosas, como uma forma de trabalho da memória. A memória entre usos e abusos é construção social dos grupos que a rememoram. $\mathrm{Na}$ atualização de sua legislação quanto aos direitos humanos o Estado Brasileiro tem encontrado dificuldades frente à própria maneira como se deu o processo de redemocratização no país. É necessário afirmar que os organizadores do regime anterior permaneceram exercendo forte influência no país e a sua maneira de narrar os acontecimentos ainda está muito latente. Não há no Brasil uma vontade de esquecimento por parte da sociedade, um querer não-lembrar. Não podemos narrar tudo, contudo novas narrativas que existam ou ainda venham a surgir são um passo ao não-dito - esta é apenas uma das expectativas da sociedade com relação a esta Comissão. Não vivemos no Brasil um período como Vichy, nos moldes e nas proporções deste, um partido comunista e um partido gaullista estabelecendo um mito assentado no resistencialismo, que teria se dado frente à ocupação nazista, que anos depois se quebrou com Le miroir brisé e Le Chagrin et la Petié, e que gerou intenso debate na França. Todavia, vivemos no Brasil reminiscências da ditadura que se expressa por meio das falas que a negam ou a justificam, de símbolos que a revivem (como nome de praças, cidades ou salas de instituições públicas), em atitudes (ou na falta dela), como na manutenção da Lei de Anistia pelo STF. Acompanhamos historicamente um processo de redemocratização, em que os militares e seus partidários gozam e exercem influência.

Uma Comissão da Verdade ou um julgamento (recordemos que a comissão não terá caráter jurisdicional ou persecutório) possivelmente não abarcará, nem agradará a todos, e nem finalizará as inquietações sobre uma época, mas será uma resposta ao não-dito, fruto da negligência, do não-agir, e também aquele mal que o homem faz a outro homem, situado na maldade íntima do criminoso, irreparável do lado dos efeitos, imprescritível do lado da justiça penal, imperdoável do lado do juízo moral. Que novo quadro teremos a partir dos resultados desta Comissão? Sente-se, repetimos a necessidade de se lembrar o passado, de se atribuir culpas e de se reconhecer o sofrimento das vítimas da repressão, como constatou o estudo, solicitado pela Comissão de Anistia do Ministério da Justiça para Revista Anistia Política e 
Justiça de Transição. (BRITO, 2009: 56) Mas e apesar de tudo é com uma perspectiva otimista, que finalizamos com as palavras de Ruth Teitel que assim analisa o fato do Brasil discutir tais temas.

O que é fantástico no caso brasileiro é que, mesmo sem as formalidades dos julgamentos, foram sendo discutidas e implementadas inúmeras medidas do "menu" da justiça transicional, e isso não eliminou o debate público no tempo. Muito pelo contrário, o debate foi desenvolvendose. $O$ fato de o Brasil hoje estar debatendo a criação de uma comissão da verdade ou a possibilidade de punir certos delitos do regime é, em si, fantástico, uma vez que demonstra esse amadurecimento do debate público sobre o tema. Há alguns anos seria inimaginável que pessoas com visões absolutamente distintas do passado e com posições ideológicas absolutamente diversas pudessem se sentar à mesa para debater essas questões, e hoje isso está acontecendo. Isso é um indicador claro de que a democracia está avançando, mesmo que esse processo não produza um resultado material concreto neste momento. Ao fim e ao cabo, uma transição reflete também uma mudança de interpretação, e é por isso que muitas transições podem ocorrer mesmo sem a mudança das pessoas na administração pública ou uma grande reforma das instituições. ${ }^{13}$

\section{Bibliografia}

DA SILVA, H.R.Kleber (org.) A luta pela Anistia. São Paulo: Ed. Unesp/Arquivo Público do Estado de São Paulo/Imprensa Oficial do Estado de São Paulo, 2009.

BURKE, P. Variedades de História Cultural. São Paulo - Rio de Janeiro: Civilização Brasileira, 2000.

GAGNEBIN, Jeanne Marie. Lembrar escrever esquecer. São Paulo: Ed. 34, 2006.

PEREIRA, Anthony W. Ditadura e repressão: o autoritarismo e o Estado de Direito no Brasil, no Chile e na Argentina. São Paulo: Paz e Terra, 2010.

PETIT, Philippe \& ROUSSO, Henry. “Quel tribunal pour l'histoire”. In: Raison Présente, n. 128. 1998.

Revista Anistia Política e Justiça de Transição. N. 1 - Brasília: Ministério da Justiça, 2009.

N. 3 - Brasília: Ministério da Justiça, 2010.

RICOUER, P. A memória, a história, o esquecimento. Campinas: Editora da Unicamp, 2008.

SANTOS, Boaventura de Sousa et al. Repressão e Memória Política no Contexto Ibero-Brasileiro: estudos sobre Brasil, Guatemala, Moçambique, Peru e Portugal. -- Brasília: Ministério da Justiça, Comissão de Anistia; Portugal: Universidade de Coimbra, Centro de Estudos Sociais, 2010.

SANTOS, Cecília Macdowell. "A justiça ao serviço da memória: mobilização jurídica transnacional, direitos humanos e memória da ditadura." In: Desarquivando a ditadura: memória e justiça no Brasil. SANTOS, C.M; TELES, E; TELES. J, A. (Orgs). São Paulo: Editora HUCITEC, 2009.

TODOROV, Tzvetan. Memoria del mal, tentación del bien - Indagación sobre el siglo XX. Barcelona: Ediciones Península, 2002.

Documentos oficiais consultados:

\footnotetext{
${ }^{13}$ Entrevista concedida por RUTI G. TEITEL já assinalada acima para Revista Anistia Política e Justiça de Transição (2010: 37)

Em Tempo de Histórias

Publicação do Programa de Pós-Graduação em História da Universidade de Brasília (PPGHIS/UnB)

No. 23, Brasília, ago. - dez. 2013

ISSN 2316-1191
} 
Decisões judiciais

Arguição de Descumprimento de Preceito Fundamental (ADPF - 153). Ordem dos Advogados do Brasil/Conselho Federal. Brasília-DF. 2010.

Corte Interamericana de Direitos Humanos. Caso Gomes Lund e outros ("Guerrilha do Araguaia) vs. Brasil. Sentença de 24 de novembro de 2010.

Projetos de lei

Brasil. Programa Nacional de Direitos Humanos (PNDH-3). Brasília: Secretaria de Direitos Humanos da Presidência da República -- rev. e atual. SDH/PR, 2010.

Projeto de Lei n. 7.376/2010, que cria a Comissão Nacional da Verdade, no âmbito da Casa Civil da Presidência da República. 